\title{
The Psychological Consequences of Fame: Three Tests of the Self-Consciousness Hypothesis
}

\author{
Mark Schaller \\ University of British Columbia
}

\begin{abstract}
Three investigations tested the hypothesis that the attainment of fame leads to chronic self-consciousness. One of these studies also examined the relationship of self-consciousness. with self-destructive behavior. Analyses of Kurt Cobain's and Cole Porter's song lyrics indicated increased use of first-person singular pronouns after each songwriter attained celebrity. An analysis of John Cheever's short stories indicated greater use of the firstperson narrative voice following his first brush with fame. Other analyses revealed that variations in Cheever's fame were positively correlated with use of first-person singular pronouns in his private letters and journals. These measures of self-consciousness-were_also_positively_correlated_with-Cheever's self-reported alcohol use. Together, these three studies offer the first empirical support for a self-consciousness hypothesis linking celebrity to self-destructive behavior.
\end{abstract}

In the urge to find a better, more perfect self, the possibility of uncovering a worse, more misshapen one hangs like a threatening cloud. Lurking behind every chance to be made whole by fame is the axman of further dismemberment. (Braudy, 1986, p. 8)

Preparation of this article was supported in part by a grant funded by the Montana Science and Technology Alliance. Victoria Kent, Rose Qualley, and Eric Schaller contributed to the development of the research reported in this article. Bruce Hietela, Aaron Kent, and Jessica Sletten assisted with data collection. I thank them all. Correspondence concerning this article may be addressed to Mark Schaller, Department of Psychology, University of British Columbia, Vancouver, BC, Canada V6T 1Z4. E-mail: schaller@cortex.psych.ubc.ca.

Journal of Personality 65:2, June 1997.

Copyright $\odot 1997$ by Duke University Press. 
Fame exerts an odd and contradictory power in contemporary Western culture. On the one hand, fame is attractive and alluring. On the other hand, celebrities often indicate that their fame is stressful and unpleasant. Fame might even be dangerous; there are numerous examples of celebrities who die miserably or who destroy themselves through self-abuse.

These perceptions of fame are based in large part on subjective perceptions and anecdotes filtered through the distorting lens of the media. What does scientific research reveal about the psychological consequences of fame? Not much. There are sophisticated analyses of the personal, situational, and historical variables that serve as antecedents to the achievement of eminence or fame in the first place (Ludwig, 1995; Simonton, 1991, 1994), but there is little empirical work explicitly attending to the psychological consequences of fame.

Within the spotty scientific literature exploring the consequences of fame, there is some evidence that is indirectly consistent with the anecdotal observation that fame can be stressful, unpleasant, and dangerous. Children of eminent people are at increased risk for drug abuse (Wellisch, 1984), but those studies are not specifically germane to the consequences of fame for the famous people themselves. More relevant are qualitative analyses identifying problems and dilemmas that are perhaps unique to famous people (Kucharski, 1984; Loy \& Brown, 1982). One study that used qualitative, participant-observer methods concluded that college athletes undergo stressful changes in their selfconcept as a consequence of experience with fame (Adler \& Adler, 1989). Also relevant is quantitative research indicating that people who have various forms of distinctive "master status" are particularly mindful and observant in their interactions with others (Frable, Blackstone, \& Scherbaum, 1990), suggesting that there are important cognitive stressors associated with distinctiveness.

So, although conceptual and empirical clues indicating certain negative consequences of fame exist, it remains unclear whether famous people are more vulnerable to misery and self-abuse. It also remains unclear as to what psychological mechanisms might account for this vulnerability. In this article, I advance the hypothesis that fame may ultimately make some people more vulnerable to certain forms of selfabuse in part because it leads to higher levels of self-consciousness. 


\section{The Self-Consciousness Hypothesis}

Fame is associated with at least two circumstances that can lead to greater levels of self-focused attention. First, because other people are aware of them, famous people are more likely to be aware that other people are aware of them. Thus, they are more likely than nonfamous people to view themselves through the eyes of others-to become "objectively self-aware" (Duval \& Wicklund, 1972). Such states of objective self-awareness may be rare or ephemeral for most people; but for public figures the presence of an audience is relatively enduring, and so the accompanying self-consciousness may be both unavoidable and chronic.

Second, famous people are different from the majority of others who are less distinguished or less famous. In a sense, becoming famous conveys entrance into an exclusive group. Research has revealed that people become increasingly self-attentive as the relative size of their group diminishes (Mullen, 1983, 1987). The relative size of the group to which a famous person belongs is tiny indeed, and often enduring, suggesting again that self-focused attention may be intense and persistent.

This analysis suggests that the onset of fame will lead to heightened and chronic levels of self-consciousness. How might this relation help to explain possible self-destructive tendencies among celebrities? An answer demands some attention to the complicated sequelae of selfconsciousness.

\section{Consequences of Fame-Induced Self-Consciousness}

Although temporary self-awareness may focus one's attention on specific aspects of one's behavior and experiences, it seems likely that chronic self-consciousness may lead to a "global evaluation of self at a more abstract level" (Gibbons, 1990, p. 290). Accompanying this global evaluation of self may be the tendency to compare oneself against successful others or against one's own "ideal self" (Duval \& Wicklund, 1972; Gibbons, 1990). Comparison to one's ideal self may not always be unpleasant, but "prolonged self-focus will eventually uncover some perceived personal shortcomings, causing discomfort" (Gibbons, 1990, p. 291). Indeed, the affective states associated with self-consciousness are predominantly negative (e.g., Pyszczynski \& Greenberg, 1987; Scheier \& Carver, 1977; see Gibbons, 1990, for a review). Therefore, 
self-consciousness may function as a motivational state, compelling the self-conscious individual to act in ways designed to reduce the aversive affective consequences.

Two subsets of strategic responses are typically used to cope with the negative affective consequences of self-consciousness (Gibbons, 1990). One strategy is to reduce the discrepancy between one's real and ideal self. A person might achieve this by behaving in such a way as to attain the ideal, or by lowering the level of his or her ideals to more realistic levels. This strategy is not likely to be effective for the celebrity, however. Given that the culture of fame often exaggerates expectations beyond a level that can be attained with any regularity, attainment of ideals may be impossible. Revision of ideals may also be difficult because the expectations or ideals to which public figures respond are not fully under their own control but may instead reflect the ideals imposed by others (cf. Higgins, 1987).

If attempts to resolve the discrepancy between real and ideal selves seem fruitless, famous people may consider an alternative strategy: to engage in some behavior to help them escape from the experience of self-consciousness. For instance, a celebrity may choose to retreat from the public eye into relative seclusion. Not all choices are so benign; a number of dangerous and ultimately self-destructive behaviors may also serve the same function (Baumeister, 1990, 1991). For instance, there is evidence that people may use alcohol and other drugs strategically as a means of escaping the aversive state of selfconsciousness (Hull, Levenson, Young, \& Sher, 1983; Hull \& Young, 1983; Hull, Young, \& Jouriles, 1986).

This analysis suggests that, although self-consciousness may have a number of possible consequences, for celebrities the consequences may be particularly unpleasant and enduring and may place the celebrity at greater risk for strategic self-destruction.

It is important, however, not to oversell the conceptual link from fame to self-destructive tendencies. Certainly not all famous people cope with the psychological stresses of fame by escaping into substance abuse or other self-destructive behaviors. Given that selfesteem appears to moderate the duration and consequences of self-awareness (Gibbons, 1990; Hull \& Young, 1983), individual differences related to self-esteem may operate as premorbid risk factors for the dangers of celebrity. The negative consequences of fame may manifest primarily among people who are already at some risk for chronic self-consciousness or self-destruction. 


\section{Overview of the Present Research}

Given the foregoing conceptual analysis, three separate investigations focused on famous individuals who were known to have had problems with substance abuse. These studies offered the first empirical tests of the self-consciousness hypothesis. It was predicted that, for these individuals, the advent of fame would be associated with an increased tendency toward chronic self-consciousness. One of these three investigations also tested the hypothesis that increased self-consciousness would be associated with an increase in self-destructive behavior, specifically, alcohol use.

Studying famous people who were known to have engaged in selfdestructive behavior does not in any way guarantee support for the self-consciousness hypothesis. The hypothesis is supported only if the data reveal that over the course of each person's life, variations in fame were significantly associated with variations in self-consciousness. Similarly, the second hypothesis is supported only if variations in self-consciousness over time were significantly associated with variations in alcohol use.

The methodological strategy in these studies might be described as "single-case quantitative analysis" (e.g., Hilliard, 1993; Jones, Ghannam, Nigg, \& Dyer, 1993) or "single-case historiometry" (Simonton, 1989). Each investigation focused on a single famous person. Unlike traditional qualitative case-study approaches that are prone to biases in data gathering and often suffer from the inabilities to test statistical significance, the present approach was quantitative, using defensibly objective data and submitting these data to statistical analyses. The approach was longitudinal, assessing relationships between conceptual variables over time.

The subjects (it seems inaccurate to call them "participants") were Kurt Cobain, Cole Porter, and John Cheever.

\section{METHOD}

\section{Case 1: Kurt Cobain}

Suffering from depression and addicted to narcotics, Kurt Cobain committed suicide in April 1994 at the age of 27. At the time, he was the lead singer and songwriter for the popular band Nirvana. The Nirvana oeuvre consists of four albums of original material. The songs on two of these albums (Bleach, Incesticide) were written while Nirvana was still relatively obscure and had not yet 
signed with a major label. The songs on the other two albums (Nevermind, In utero) were written after Nirvana had signed with a major recording label. The songs on the last of these two albums were written after Nirvana had attained widespread popularity as a result of their previous, hugely successful album. As a result of Nirvana's increasing popularity during this time, it was expected that Cobain's song lyrics would indicate increasing self-consciousness.

Analytic strategy. To test the self-consciousness hypothesis, a before/after strategy was used. One comparison tested the hypothesis that Cobain would be more self-conscious after Nirvana signed a contract with a major record label. A second comparison tested the hypothesis that Cobain would be even more self-conscious after Nirvana's first major-label album became hugely popular.

Operationalization of self-consciousness. In much previous research, investigators have used pronouns and self-referential statements as indicators of selffocused attention (e.g., Berkowitz, 1987; Greenberg \& Pyszczynski, 1986; Hull et al., 1983). The present investigation used a variant of these procedures.

Among the 53 songs that appear on Nirvana's four albums of original material, there are 46 different songs written by Cobain. Complete lyrics for these 46 songs were obtained from an fip (file transfer protocol) site on the Internet. A trained coder counted the total number of pronouns in each of these song lyrics. The same coder counted the total number of first-person singular (I, me, my, mine, myself) pronouns in each song. For each song, a percentage was computed by dividing the number of first-person singular pronouns by the total number of pronouns. This percentage served as an indicator of self-consciousness. ${ }^{1}$

\section{Case 2: Cole Porter}

Cole Porter (1891-1964) was one of the most prolific American songwriters of the 20th century. He wrote hundreds of songs over a career that spanned four decades, from the early 1910 s to the mid-1950s. Porter was an alcoholic and appeared to suffer from depression. In 1951 he spent several months undergoing electroshock therapy. According to biographical reports (Schwartz, 1977), Porter's professional standing and popular fame were secured toward the end of 1929, at which time three musicals that he wrote opened almost simultaneously on Broadway. From that point on, it appears, Porter was a public

1. The pronoun-counting approach to self-consciousness appears to have been highly reliable. A subset of Cobain's lyrics was coded by a second rater, and the interrater reliability was .93 . 
figure. $^{2}$ It was expected that Porter's song lyrics would indicate increased self-consciousness following the advent of his fame.

Analytic strategy. As with Cobain, a before/after strategy was pursued with Cole Porter. The key comparison(s) tested the hypothesis that Porter would be more self-conscious after his attainment of fame in 1929 than before.

Operationalization of self-consciousness. An attempt was made to select two songs written during each year of Porter's songwriting career (approximately 1910-1957). The method of song selection was as follows: (a) For each year, the two songs selected were the first two songs printed in the book The Complete Lyrics of Cole Porter (Kimball, 1983) associated with that year. (b) Songs were selected only if there was clear indication of copyright, publication, or performance date. (c) If only a performance date was indicated and that performance date fell in either January or February of a year, the song was selected as representative of the previous year. $(d)$ In cases where multiple years were associated with a selected song, the song was assigned to the earliest indicated year. (When possible, a biographical source [Schwartz, 1977] was used to verify the year in which a song was written.) (e) Songs were selected only if written for a single voice; multiple-part lyrics were avoided. As a result of these constraints, two songs were selected for each of 37 different years spanning the period from 1910 to 1957 (lyrics were not available for every year during this time). Selections for each year were made before reading the lyrics of those selections.

A trained coder counted the total number of pronouns across the two songs selected for each year. The same coder counted the total number of first-person singular pronouns across the two songs for each year. For each year, a percentage was computed by dividing the number of first-person singular pronouns by the total number of pronouns. This percentage served as the index of self-consciousness.

\section{Case 3: John Cheever}

John Cheever (1912-1982) was one of the most distinguished American fiction writers of the second half of the 20th century. He won a National Book

2. Objective measures of fame buttress the judgment of Porter's biographers. Prior to 1930, Porter's name had appeared a total of only five times in the New York Times Index and the Reader's Guide to Periodical Literature, and never more than twice in one year. In 1930 alone, there were seven articles mentioning Porter in the New York Times. Over the course of the 1930s, there were 30 total citations to Porter across the two indexes. Porter continued to be a public figure through the 1940 s (15 total citations) and 1950 s (32 total citations). 
Award in 1958 for his first novel and wrote several other acclaimed novels. He was perhaps best known for his short stories, and his collection The Stories of John Cheever was awarded the Pulitzer Prize in 1978. He suffered from alcoholism throughout most of his adult life; he entered an alcohol treatment program in 1975, after which time he remained sober. His fame charted a somewhat different course from that of either Cobain or Porter. There is no clear point at which Cheever crossed a threshold from obscurity into celebrity. Instead, his career seems marked by certain short-lived spikes of fame rather than any truly chronic celebrity. He achieved a certain acclaim when he won the National Book Award, but the public recognition was not sustained. In 1964, Cheever appeared on the cover of Time, but again there is little evidence that he was a publicly recognized celebrity for very long. His daughter's memoir indicates that he did not feel that he had truly achieved any sort of lasting success or fame until the late 1970s, just a few years before he died (S. Cheever, 1984).

Analytic strategy. Given the uneven trajectory of Cheever's celebrity, several strategies were pursued for testing the self-consciousness hypothesis. A before/after strategy tested the hypothesis that the fame Cheever achieved periodically following receipt of the National Book Award (in 1958) would be associated with a level of self-consciousness higher than he experienced prior to 1958. A correlational strategy also was pursued, testing the hypothesis that the waxing and waning of his celebrity would be associated with a waxing and waning of self-consciousness.

Cheever's writings also provided an opportunity to test the secondary hypothesis that he may have used alcohol strategically as a means of coping with chronic self-consciousness. The only meaningful way to test this hypothesis was with a correlational strategy. It was expected that variations over time in self-consciousness would be correlated with variations in alcohol use.

Operationalization of self-consciousness. A collection of short stories-The Stories of John Cheever (J. Cheever, 1978)-served as the source for a measure of self-consciousness subjected to the before/after analysis. Each of the 60 stories in the collection was identified as being narrated in either the firstor third-person voice. It is not always clear exactly when each story was written, but based upon Cheever's own indication that the 60 stories in the collection are presented in chronological order (J. Cheever, 1978, p. ix) and biographical accounts that help to identify the year in which certain key stories were written (Donaldson, 1988), it was judged that the first 25 stories in the collection were written prior to Cheever's receipt of the National Book Award (1946-1957) and the last 35 were written afterward (1958-1977).

For the sake of the correlational analyses, two sources of more personal writings were used to generate measures of self-awareness specific to certain 
years. The Letters of John Cheever (B. Cheever, 1988) presents a number of personal letters written by Cheever spanning a period from the 1930s until 1982. Given that the addressee would be expected to exert an influence on the content and style of Cheever's letters, analyses focused only on letters Cheever wrote to two long-time correspondents-Josephine Herbst and William Maxwell. Eight letters to Herbst and 9 to Maxwell were selected with the constraints that $(a)$ an attempt was made to select letters that spanned a large number of years, and $(b)$ no letters were selected after 1975 (the year Cheever entered an alcohol rehabilitation program). The 17 selected letters represented 14 different years spanning a period from 1946 to 1975. A trained coder counted the total number of pronouns and the total number of first-person singular pronouns in the letter or letters selected for each year. A percentage was computed by dividing the number of first-person singular pronouns by the total number of pronouns. ${ }^{3}$

A similar pronoun-based measure of self-consciousness was derived from The Journals of John Cheever (J. Cheever, 1991). Two full pages were selected randomly for each year from 1948 to 1982 (with the exception of 1950 and 1951, for which there are no entries). For each of the 33 selections, a coder counted the total number of pronouns and the total number of firstperson singular pronouns. A percentage was computed by dividing the number of first-person singular pronouns by the total number of pronouns.

All letters and diary entries were selected prior to coding to eliminate any possibility of selection bias.

Operationalization of fame. For the sake of the correlational analyses, fame was operationalized as the number of citations to Cheever in the New York Times Index and the Reader's Guide to Periodical Literature. For the latter, citations were counted only if they referred to a story in a nationally distributed magazine about which Cheever was the subject, but not if the periodical was obscure or if the citation was to a story that he wrote. Summing citations from these two sources ( $r=.87$ between the two citation counts), a composite quantitative indicator of fame was generated for every year from 1945 to $1982 .{ }^{4}$

Operationalization of alcohol use. Cheever did not deny his alcoholism, at least not in his private journals. Many of his journal entries depict in tragicomic detail his attempts to put off his inevitable visits to the liquor cabinet

3. A subset of Cheever's letters was coded by a second rater, and the interrater reliability was 99 .

4. These data reflect the uneven trajectory of Cheever's fame. Prior to attaining widespread renown in the late 1970 s, citation indexes indicate that there were only certain short periods earlier in his career during which he was in the public eye. These spikes of fame occurred around 1957, 1964, and 1969. Not coincidentally, these were the years during which his first three novels were published. 
Table 1

Self-Consciousness before and after Fame

\begin{tabular}{lccc}
\hline & \multicolumn{3}{c}{ Self-consciousness } \\
\cline { 3 - 4 } Famous individual & Before fame & After fame & $p$ \\
\hline Kurt Cobain & 0.506 & 0.662 & 0.07 \\
Cole Porter & 0.247 & 0.470 & 0.01 \\
John Cheever & 0.200 & 0.514 & 0.02 \\
\hline
\end{tabular}

Note. Cobain's self-consciousness was based on pronoun use in lyrics before and after signing a contract with a major record label. Porter's self-consciousness was based on pronoun use in lyrics during the 10 years before and 10 years after he attained widespread popular recognition. Cheever's self-consciousness was based on narrator voice in short stories he wrote before and after he won the National Book Award. See text for details.

during the day. In order to derive some rough estimate of Cheever's alcohol use, a trained coder counted the number of times in each two-page journal entry (the same entries used for the pronoun analysis) that Cheever mentioned his own alcohol use.

\section{RESULTS}

\section{Case 1: Kurt Cobain}

Two planned contrasts tested two separate predictions about the manner in which Cobain's use of first-person singular pronouns might be responsive to his fame. One contrast compared the song lyrics on Nirvana's first two albums (recorded for a small independent label) with the lyrics on the two major-label albums that followed. This contrast revealed a near-significant effect on the ratio of first-person singular pronouns, $t(42)=1.91, p<.07$. Following Nirvana's attainment of major-label status, the percentage of first-person singular pronouns in Cobain's song lyrics increased from 0.506 to 0.662 (see Table 1).

A second contrast compared the lyrics on Nirvana's first major-label album (which catapulted them into widespread popularity) with their next album. No effect emerged from this contrast $(t<1)$, indicating no further increase in Cobain's self-consciousness following the release of their first major-label album. 


\section{Case 2: Cole Porter}

Two different analyses tested the hypothesis that Porter's self-consciousness would be higher following his entry into the world of celebrity at the end of 1929. An analysis focusing just on the 1920s and 1930s reveals that the ratio of first-person singular pronouns in songs written during the $1930 \mathrm{~s}(M=.470)$ was significantly higher than in songs written during the $1920 \mathrm{~s}(M=.247), F(1,13)=9.22, p<.01$ (see Table 1). An analysis accounting for Porter's entire songwriting career reveals a similar difference: The ratio of first-person singular pronouns in songs written during the period $1930-1957(M=.491)$ was significantly higher than in the period 1910-1929 $(M=.274), F(1,35)=5.95, p<.02$.

\section{Case 3: John Cheever}

A before/after test of the self-consciousness hypothesis compared the narrator voice in Cheever's short stories written before and after 1958 . Results indicate that only 5 of the 25 pre-1958 stories were written in the first-person voice, whereas 18 of the 35 post-1958 stories were written in the first-person voice (see Table 1). The difference is significant, $\chi^{2}(1 ; n=60)=6.09, p<.02$. Following his first brush with public acclaim, Cheever's short stories indicate greater self-consciousness. ${ }^{5}$

Correlational analyses also yielded results consistent with the prediction that fame is related to self-consciousness. Using individual years as the unit of analysis, the composite fame measure (based on citation indexes) was significantly correlated with the ratio of first-person singular pronouns in Cheever's letters, $r(12)=.61, p<.05$. The same index was also positively correlated with the ratio of first-person singular pronouns in Cheever's private journals, $r(32)=.23$, although this latter effect was not statistically significant. The relation between fame and journal-based self-consciousness is somewhat stronger (although still not statistically significant at conventional levels) if one considers just those years prior to Cheever's sobriety in $1975, r(24)=.32 .^{6}$

5. Parallel before/after analyses were performed on measures of self-consciousness derived from Cheever's letters and journals. Means on both percentage measures were higher after 1958 (both $M s=.48)$ than before $(M s=.37$ and .43 for letters and journals, respectively). Neither difference was significant $(F \mathrm{~S}<1)$.

6. If temporary fame leads to temporarily increased self-consciousness, the effect should be fairly immediate (e.g., within the space of 1 year). For this reason, the primary correlational analyses examined the relation between fame at Year $x$ and self-consciousness at Year $x$. Additional analyses examined the possibility that there might be a 
Correlational analyses also tested for the hypothesized relation between self-consciousness and alcohol use. Only data prior to 1975 were considered. Self-reported alcohol use was not correlated with the letters-based measure of self-consciousness, $r(12)=.11$, but did correlate positively with the journal-based measures of self-consciousness, $r(24)$ $=.39, p<.05$. The correlation between fame and alcohol use was .13 .

Additional correlational analyses collapsed calendar years into 2year periods of time in order to create somewhat more reliable measures (although at the expense of halving degrees of freedom). Results yielded correlations between fame and pronoun-based measures of self-consciousness that were roughly equivalent to those reported above ( $r s>.33$ for both measures of self-consciousness, both $n s$ at conventional levels). The correlations between alcohol use and the measures of self-consciousness were stronger than those reported above: On the letters-based measures, $r(8)=.34, n s$; on the journalsbased measure, $r(11)=.65, p<.05$. Thus, regardless of how the data were aggregated, the correlations between fame, self-consciousness, and alcohol use were consistently positive.

\section{Additional Analyses: Consideration of Alternative Causal Hypotheses}

The preceding results are consistent with the prediction that the achievement of fame leads to increased self-consciousness (and that increased self-consciousness leads to increased alcohol use). However,

a time-lagged relation between fame and self-consciousness. Although the number of data points was insufficient for rigorous time-series analyses, several cruder timelagged correlational analyses were conducted. Measures of fame at Year $x$ were not correlated with the journal-based measure of self-consciousness at Year $x+1(r< \pm .04)$. Measures of fame at Year $x$ were negatively correlated with the letters-based measure of self-consciousness at Year $x+I$. This unexpected result appears to have been merely an artifact resulting from the anomalous fact that the letters-based measure of self-consciousness at Year $x$ was itself even more strongly negatively correlated with the letters-based measure of self-consciousness at Year $x+1$. Other analyses revealed no correlation between measures of fame at Year $x$ and measures of self-consciousness at Year $x-1$ (all $r s< \pm .14$ ). 
other causal explanations might also account for the observed relations. Additional analyses explored two plausible alternative hypotheses.

One plausible alternative is that fame did not lead to self-consciousness, but that some concomitant of fame led to increased self-consciousness. A possible concomitant is creative achievement (for instance, Cheever's fame-as measured by citations-was highest in those years in which his novels were published). Might fame and selfconsciousness have been independent consequences of creative output or concurrent self-promotional activities? Additional analyses suggest not. Aside from his increased fame (and self-consciousness) in years in which his novels were published, neither Cheever's fame nor selfconsciousness was significantly related to the number of short stories he published $(r s< \pm .11)$. Nor was Porter's fame or self-consciousness related to the number of songs written or musicals scored $(r s< \pm .11)$. Thus, it seems unlikely that creative achievement can account for the observed relations between fame and self-consciousness.

Another possible alternative explanation arises from the fact that chronological age was confounded with fame in the before/after analyses on Cobain, Porter, and Cheever. Might each artist simply have become increasingly self-conscious with age, regardless of fame? To test this alternative explanation on Cheever's data, Cheever's stories were numbered according to the chronological order they were written, and correlations were computed between these numbers and the voice used in each story (third-person $=0$; first-person $=1$ ). Results revealed that, in his 25 pre-1958 stories, there was no relation between chronology and voice, $r=.07$. Among the 35 post- 1958 stories, there was a moderate positive correlation between chronology and voice, $r=.28$. Thus, although there was a slight trend toward increasing use of the first-person voice toward the end of his career, there was no indication of any such trend before his initial celebrity. As for Porter, during the years prior to 1930 , there was no correlation between Porter's chronological age and self-consciousness in his song lyrics, $r(14)=-.06$. After 1930 , there was a moderate negative correlation between Porter's age and self-consciousness, $r(23)=-.26$. In fact, the before/after comparisons of Porter's self-consciousness remain significant or near significant even when controlling for Porter's age $(p<.03$ when considering his entire career; $p<.08$ when considering just the years 1920-1939). 


\section{DISCUSSION}

The study of fame does not lend itself easily to the traditional methods of scientific inquiry, but that does not mean that such inquiry is impossible. Many psychological phenomena that cannot be fitted to experimental methodologies can be examined through analyses of archival records (Simonton, 1990). In recent years, a number of hypotheses relevant to the study of human personality have been tested through analyses of writers' writings (e.g., Porter \& Suedfeld, 1981; Rosenberg, 1989; Simonton, 1989; Stewart, Franz, \& Layton, 1988). Using such a methodology, the present study offered three investigations into the psychological consequences of fame.

The results of all three investigations are consistent with the selfconsciousness hypothesis. The increased popularity and success indicated by Nirvana's "graduation" to a major-label band was accompanied by a near-significant increase in first-person singular pronoun use in Cobain's song lyrics. The percentage of first-person singular pronouns in Porter's song lyrics significantly increased-in fact, virtually doubled-after Porter became a celebrity. In a different genre, Cheever's writing also demonstrated a relationship between fame and self-consciousness. Following his first encounter with public renown, Cheever was significantly more likely to write his short stories in the firstperson voice. Although no parallel effect was revealed in his private letters and journals, other analyses of these writings revealed additional support for the self-consciousness hypothesis: Over a period of 3 decades, variations in Cheever's fame correlated positively with usage of first-person singular pronouns in his letters and journals. These results are remarkable, considering that there would have been many influences on the voices chosen and pronouns used in the creative writings of Cobain, Porter, and Cheever. Nevertheless, despite the many other influences on their writings, these results suggest that the psychological consequences of fame intruded to a significant degree.

Results from the investigation of Cheever were consistent with the additional hypothesis that famous people may engage in self-destructive behavior as a means of escaping from self-consciousness. Correlational analyses revealed some evidence that variations in Cheever's self-consciousness were positively correlated with his use of alcohol. The relation between self-consciousness and alcohol use draws tighter the connection between fame and self-destructive behavior. This indicates that increased self-consciousnesss is not merely an interesting 
psychological consequence of fame; it may also be an important determinant of the self-destructive behaviors in which famous people sometimes engage.

In all three cases studied here, the results of quantitative analyses are consistent with biographical information concerning the consequences of fame on Cobain, Porter, and Cheever (Donaldson, 1988; Fricke, 1994; Schwartz, 1977). The anecdotal evidence is especially compelling when considering Cheever. Cheever's daughter Susan wrote that "wealth and fame and love had an odd effect on my father.... He went through a kind of adolescence of celebrity. At times he seemed to be his own number-one groupie" (S. Cheever, 1984, p. 210). In his own writings, Cheever reveals the ruminative self-doubts that followed on the heels of public recognition. In a 1959 letter to Josephine Herbst, he wrote, "I'm embarrassed to find out that Joe Schrank thinks I'm on the way to getting famous. ... If I am famous why should I have a hole in the seat of my pants and not enough money for last month's bills?" (B. Cheever, 1988, p. 221).

Of course, some limitations of the present studies need to be noted. First, not every analysis revealed significant effects of fame on selfconsciousness. Although there was an increase in Cobain's self-consciousness following Nirvana's deal with a major recording label, there was no evidence of further increase in self-consciousness following the additional celebrity that followed Nirvana's first major-label album. Analyses on Cheever's data revealed a significant before/after effect of his initial fame on his short story "voice," but not on pronoun use in his journals and letters. Despite these null effects, however, the primary analyses in all three cases revealed data consistent with the self-consciousness hypothesis. Given the crudeness of the available means of operationalizing the variables under study, it is not surprising that some analyses would yield weak or unreliable effects. What is remarkable is that these crude operationalizations generally revealed statistically reliable effects that supported the specific hypotheses in each case.

Given the archival, nonexperimental nature of these data, it is impossible to claim unequivocal support for a causal effect of fame on self-consciousness. However, logical appraisals of obvious alternative causal explanations render these alternatives less plausible. Results from several analyses indicate that the apparently causal effects of fame could not simply have resulted from history or maturation effects (Cook \& Campbell, 1979). Hypotheses based upon history or maturation seem even more strained when one considers that the three subjects 
lived during different time periods and encountered fame at different ages. It also seems unlikely that the observed relations were the result of self-consciousness exerting a causal effect on celebrity (e.g., selfconscious attempts to become famous leading to fame). Any such hypothesis would necessarily predict some delay between self-consciousness and later fame. No such lag is evident in Cheever's data (see Footnote 6), or Porter's data-in which increased self-consciousness occurred after, not before, 1929. Finally, several analyses tested and largely dismissed the possibility that fame and self-consciousness were simply causally independent products of creative output or selfpromotional activities temporally coincident with creative output.

The relation between Cheever's fame and alcohol use must be interpreted with greater caution. The correlations were not statistically robust, and the measure of alcohol use was not particularly clean. The measure was based upon Cheever's own reports of his alcohol use and is not methodologically independent of the journal-based measure of self-consciousness (it is, however, independent of the letters-based measure of self-consciousness). With these limitations in mind, however, it is worth noting that this result is consistent with other theory and research linking self-awareness to alcohol use and other selfdestructive behaviors (Baumeister, 1991).

Finally, the methodological approach chosen here raises questions about the generality of these results. The self-consciousness hypothesis is idiographic, focusing on changes over time within the same person. As others have noted, this sort of hypothesis is appropriately studied with intra-subject (as opposed to inter-subject) methodologies such as the single-case quantitatively analyses reported here (Hilliard, 1993; Thorngate, 1986). The drawback of this sort of methodology, however, is that generality of findings requires replication on a case by case basis. Although it is reassuring that the self-consciousness hypothesis is supported in all three cases, the reader will note certain similarities among Cobain, Porter, and Cheever. All three were men. All three men were writers (albeit of very different sorts) who achieved fame largely because of their creative output. And all three men were chosen for study because they were known to have exhibited self-destructive tendencies. Replication across more cases would yield yet greater support for the predicted effect of fame on self-consciousness.

Of perhaps greater conceptual interest than direct replication would be systematic replication exploring those variables that might moderate the effects of fame on self-consciousness. Given the many 
antecedents of fame and the many forms that fame might take, it seems likely that the consequences of fame may take many forms as well. At the outset, I noted that fame may have its most deleterious effects on individuals who are already at risk for self-destructive behavior. Cobain suffered from low self-esteem as an adolescent. Porter and Cheever both emerged from families with histories of alcoholism. It could be argued that each was at risk for self-destructive behavior in the first place, and their fame served as a catalyst for the realization of that unhealthy potential.

If the negative consequences of fame manifest primarily among people who are already at risk for self-destruction, it would be interesting to consider further the possible moderating role of self-esteem. People with uncertain self-esteem might be most likely to need and seek the approval of others; they might have the greatest "urge to find a better, more perfect self . . to be made whole by fame" (Braudy, 1986 , p. 8). Future research might test the ironic possibility that those people who most crave fame might also be especially likely to find lurking behind it the psychological axman of dismemberment.

\section{REFERENCES}

Adler, P. A., \& Adler, P. (1989). The glorified self: The aggrandizement and the constriction of self. Social Psychology Quarterly, 52, 299-310.

Baumeister, R. F. (1990). Suicide as escape from self. Psychological Review, 97, 90-113.

Baumeister, R. F. (1991). Escaping the self. New York: Basic Books.

Berkowitz, L. (1987). Mood, self-awareness, and willingness to help. Journal of Personality and Social Psychology, 52, 721-729.

Braudy, L. (1986). The frenzy of renown. New York: Oxford University Press.

Cheever, B. (1988). The letters of John Cheever. New York: Simon and Schuster.

Cheever, J. (1978). The stories of John Cheever. New York: Knopf.

Cheever, J. (1991). The journals of John Cheever. New York: Knopf.

Cheever, S. (1984). Home before dark. Boston: Houghton Mifflin.

Cook, T. D., \& Campbell, D. T. (1979). Quasi-experimentation. Boston: Houghton Mifflin.

Donaldson, S. (1988). John Cheever: A biography. New York: Delta.

Duval, S., \& Wicklund, R. A. (1972). A theory of objective self-awareness. New York: Academic Press.

Frable, D. E. S., Blackstone, T., \& Scherbaum, C. (1990). Marginal and mindful: Deviants in social interactions. Journal of Personality and Social Psychology, 59, 140-149.

Fricke, D. (1994, December 15). Courtney Love. Rolling Stone, 697. 
Gibbons, F. X. (1990). Self-attention and behavior: A review and theoretical update. In M. P. Zanna (Ed.), Advances in experimental social psychology (Vol. 23, pp. 249-303). San Diego: Academic Press.

Greenberg, J., \& Pyszczynski, T. (1986). Persistent high self-focus after failure and low self-focus after success: The depressive self-focusing style. Journal of Personality and Social Psychology, 50, 1039-1044.

Higgins, E. T. (1987). Self-discrepancy: A theory relating self and affect. Psychological Review, 94, 319-340.

Hilliard, R. B. (1993). Single-case methodology in psychotherapy process and outcome research. Journal of Consulting and Clinical Psychology, 61, 373-380.

Hull, J. G., Levenson, R. W., Young, R. D., \& Sher, K. R. (1983). Self-awarenessreducing effects of alcohol consumption. Journal of Personality and Social Psychology, 44, 461-473.

Hull, J. G., \& Young, R. D. (1983). Self-consciousness, self-esteem, and success-failure as determinants of alcohol consumption in male social drinkers. Journal of Personality and Social Psychology, 44, 1097-1109.

Hull, J. G., Young, R. D., \& Jouriles, E. (1986). Applications of the self-awareness model of alcohol consumption: Predicting patterns of use and abuse. Journal of Personality and Social Psychology, 51, 790-796.

Jones, E. E., Ghannam, J., Nigg, J. T., \& Dyer, J. F. P. (1993). A paradigm for singlecase research: The time series study of a long-term psychotherapy for depression. Journal of Consulting and Clinical Psychology, 61, 381-394.

Kimball, R. (1983). The complete lyrics of Cole Porter. New York: Knopf.

Kucharski, A. (1984). On being sick and famous. Political Psychology, 5, 69-81.

Loy, P., \& Brown, P. (1982). Red hot mamas, sex kittens, and sweet young things: Role engulfment in the lives of musical comedy performers. International Journal of Women's Studies, 5, 338-347.

Ludwig, A. M. (1995). The price of greatness. New York: Guilford.

Mullen, B. (1983). Operationalizing the effect of the group on the individual: A selfattention perspective. Journal of Experimental Social Psychology, 19, 295-322.

Mullen, B. (1987). Self-attention theory: The effects of group composition on the individual. In B. Mullen \& G. R. Goethals (Eds.), Theories of group behavior (pp. 125-146). New York: Springer-Verlag.

Porter, C. A., \& Suedfeld, P. (1981). Integrative complexity in the correspondence of literary figures: Effects of personal and societal stress. Journal of Personality and Social Psychology, 40, 321-330.

Pyszczynski, T., \& Greenberg, J. (1987). Self-regulatory preservation and the depressive self-focusing style: A self-awareness theory of reactive depression. Psychological Bulletin, 102, 122-138.

Rosenberg, S. (1989). A study of personality in literary autobiography: An analysis of Thomas Wolfe's Look Homeward, Angel. Journal of Personality and Social Psychology, 56, 416-430.

Scheier, M. F., \& Carver, C. S. (1977). Self-focused attention and the experience of emotion: Attraction, repulsion, elation, and depression. Journal of Personality and Social Psychology, 35, 625-636.

Schwartz, C. (1977). Cole Porter: A biography. New York: Dial. 
Simonton, D. K. (1989). Shakespeare's sonnets: A case of and for single-case historiometry. Journal of Personality, 57, 695-721.

Simonton, D. K. (1990). Psychology, science, and history: An introduction to historiometry. New Haven: Yale University Press.

Simonton, D. K. (1991). Emergence and realization of genius: The lives and works of 120 classical composers. Journal of Personality and Social Psychology, 61, 829-840.

Simonton, D. K. (1994). Greatness. New York: Guilford.

Stewart, A. J., Franz, C., \& Layton, L. (1988). The changing self: Using personal documents to study lives. Journal of Personality, 56, 41-76.

Thorngate, W. (1986). The production, detection, and explanation of behavioral patterns. In J. Valsiner (Ed.), The individual subject and scientific psychology (pp. 71-93). New York: Plenum.

Wellisch, D. K. (1984). Drug problems in children of the wealthy and famous. Journal of Drug Issues, 14, 233-242. 
This document is a scanned copy of a printed document. No warranty is given about the accuracy of the copy. Users should refer to the original published version of the material. 